\title{
Description of a standardized rehabilitation program based on sub-maximal eccentric following a platelet-rich plasma infiltration for jumper's knee
}

\author{
Jean-François Kaux ${ }^{1}$ \\ Bénédicte Forthomme ${ }^{2}$ \\ Marie-Hélène Namurois ${ }^{2}$ \\ Philippe Bauvir ${ }^{2}$ \\ Nathalie Defawe ${ }^{2}$ \\ François Delvaux ${ }^{2}$ \\ Cédric Lehance ${ }^{2}$, \\ Jean-Michel Crielaard ${ }^{1}$ \\ Jean-Louis Croisier ${ }^{2}$
1 Physical Medicine and Sports Traumatology De- partment, University and University Hospital of Liège, Belgium ences, University and University Hospital of Liège, Belgium \\ 2 Physiotherapy Service, Department of Motility Sci-
}

Corresponding author:

Jean-François Kaux

Physical Medicine and Sport Traumatology, University Hospital of Liège

Avenue de l'Hôpital, B35, 4000 Liège, Belgium

E-mail: jfkaux@chu.ulg.ac.be

\section{Summary}

Introduction. Different series emphasized the necessity of rehabilitation program after infiltration of platelet-rich plasma (PRP) in case of tendinopathy. However, most of them describe only briefly the reeducation protocol and these programs vary. Our aim was to extensively describe a specific standardized rehabilitation program. Methods. After a review of literature of post-PRP infiltration protocols, we had developed a standardized rehabilitation protocol. This protocol was evaluated by 30 subjects with chronic jumper's knee who. A standardised progressive sub-maximal eccentric program supervised by a physical therapist for 6 weeks was started 1 week post-infiltration. The patient benefited also from electromyostimulation, isometric strengthening and stretching of the quadriceps, cycloergometer and cryotherapy. After the supervised program, the patient had to make an auto-reeducation added to the reathletisation protocol for 6 more weeks which was followed by maintenance exercises up to 1 year. The assessments were made using a VAS, IKDC and VISA-P scores.
Results. The VAS, IKDC and VISA-P scores decreased very significantly with time. The compliance to auto-reeducation was good.

Conclusions. We proposed a simple and efficient protocol based on sub-maximal eccentric reeducation to add to PRP infiltrations in case of patellar tendinopathy.

KEY WORDS: jumper's knee, eccentric exercises, plateletrich plasma, $P R P$, rehabilitation, protocol.

\section{Introduction}

One quarter of athletes treated for a knee injury is diagnosed with tendinopathy. The most common knee disorder is jumper's knee, especially among jumping sports like volleyball and basketball ${ }^{1}$. Moreover, these conditions remain often rebel to conservative management including eccentric reeducation and shock wave therapy 1 . Injections of platelet-rich plasma (PRP) are used for tendinopathy with the aim of providing cellular and humoral mediators to induce healing in areas of degeneration$^{2}$. PRP is prepared from autologous whole blood, which is centrifuged to concentrate platelets in plasma ${ }^{2}$. The intention is to augment the natural healing process at the site of pain through the action of growth factors (GFs) (PDGF, IGF-1, VEGF, bFGF, TGF- $\beta$ 1, EGF ...) to promote matrix synthesis and wound healing ${ }^{3}$. Moreover, it has been demonstrated on rat tendons that a mechanical stimulation optimise the healing process of a tendon after PRP use ${ }^{4}$. It has also been demonstrated on rats, that eccentric training is more efficient than concentric training to improve tendon biomechanical properties $^{5}$. Moreover, this mechanical stimulation should initiate as soon as possible after PRP infiltration because platelet stimulates especially the early phases of tendon healing process ${ }^{3}, 4$. Among human, different series emphasized the necessity of rehabilitation program after the infiltration of PRP to improve the efficacy of this treatment ${ }^{6}$. However, most of the studies describe only briefly the reeducation protocol and these programs vary a lot between themselves 6 . Based on literature and our clinical experience, we developed a standardized, post-PRP infiltration, sub-maximal eccentric program ${ }^{7}$.

\section{Material and methods}

\section{Literature analysis}

The electronic databases Medline and Scopus were searched (until March 31, 2014). Selected literature 
was limited to original articles and to English and French language peer-reviewed journals. The keywords and their synonyms used have allowed for a systematic research. We used existing MeSH (Medical Subject Heading) alone or in combination. They consisted of synonyms for "platelet-rich plasma", "growth factors" and "patellar tendinopathy". Studies with a high level of evidence were considered preferentially. As it is a recent treatment, there are currently few studies with a high level of evidence. Therefore, articles with a low level of evidence were also included in this review of the literature.

\section{Our rehabilitation protocol}

Rehabilitation program

After 5 to 7 days of relative rest (after the infiltration of PRP), while they could have a little local inflammatory reaction with increase of pain, they started a standardised progressive sub-maximal eccentric program supervised by a physical therapist, three times a week, for 6 weeks (Tab. 1). The eccentric exercise was realized using the weight of the patient's body. The patient started with the back against the wall. On the pathological leg (the left side in this case), he would then slide slowly his back down the wall until his leg would be bent at a certain angle. Next, he had to push on both legs to return to the starting position. The angulation and the number of sessions were progressively increased during the reeducation, respectively from $45^{\circ}$ to $60^{\circ}$ and $90^{\circ}$ and from 3 to 5 sessions of 15 to 20 repetitions, following the Stanish criteria ${ }^{8}$. In case of no pain, after 6 weeks, eccentric exercises would be done on a decline board of $25^{\circ 9}$. Thirty seconds of rest were allowed between the sessions.

The patient benefited also from isometric strengthening (e.g. quadriceps drill) and passive stretching of the quadriceps, 20 minutes of electromyostimulation $(50 \mathrm{~Hz})$, and 10 minutes of cryotherapy. Ten minutes of cycloergometer with low resistance were also added to the program after 2 post-infiltrative weeks. After the supervised program, the patient had to make an auto-reeducation added to the reathletisation protocol for 6 more weeks which is followed by maintenance exercises ( 2 times a week) up to 1 year.

\section{Outcome measurements}

The assessments were made using different scores as in our previous studies ${ }^{7}$ :

- 10-point Visual Analogic Scale (VAS);

- International Knee Documentation Committee form (IKDC);

- Victorian Institute of Sport Assessment - Patellar questionnaire (VISA-P).

The whole evaluation was made before the infiltration of PRP, 6 weeks, 3 months and 1 year after the injection of PRP.

The mean score of compliance with the auto-reeducation was calculated using a scale from 0 (no compliance) to 10 (maximum compliance).

\section{Statistics}

Results were expressed as the mean \pm standard deviation of the mean (SD). Changes over time were assessed using generalised linear mixed models (GLMM). Pearson correlation coefficients were used to assess the relationship between changes in various outcomes. Statistical analyses were done with the software Statistical Analysis System, version 9.1 (SAS Institute, Caro, NC) and a level of significance was set at $1 \%$.

This study meets the ethical standards of the journal ${ }^{10}$.

\section{Results}

\section{Literature results}

A total of 12 articles were selected ${ }^{7,11-21}$. The post-infiltrative of the protocol of all these studies included reeducation or exercises programs. Most of them (8/12) recommended eccentric exercises ${ }^{7,11-17}$. The other (3/12) recommended only stretching and isometric and isotonic strengthening programs ${ }^{18-20}$. One series did not describe the rehabilitation protocol at all ${ }^{21}$. From the 12 selected series, only 3 studies described more extensively their post-infiltrative rehabilitation protocol $7,15,16$. The delay before starting exercises or rehabilitation vary a lot among series (from 24 hours to 1 month).

Noticed that many different techniques of PRP preparation were used leading to different PRP concentrations ${ }^{22}$.

\section{Results of our rehabilitation protocol}

The VAS decreased very significantly with time $(p<0.0001)$, from $5.8 \pm 1.6$ before infiltration to $3.3 \pm$ 2.4 at 6 weeks, $2.5 \pm 2.3$ at 3 months, and $1.4 \pm 2.3$ at 1 year (Fig. 1a).

The IKDC score increased very significantly with time $(p<0.0001)$, from $48.5 \pm 11.9$ before infiltration to 58.7 \pm 19.3 at 6 weeks, $60.5 \pm 19.6$ at 3 months, and 76.9 \pm 19.5 at 1 year (Fig. $1 \mathrm{~b}$ ).

The VISA-P score increased very significantly with time $(p=0.0002)$, from $47.3 \pm 16.0$ before infiltration to $59.0 \pm 21.0$ at 6 weeks, $64.3 \pm 21.5$ at 3 months, and $74.3 \pm 20.1$ at 1 year (Fig. 1c).

The compliance to auto-reeducation was $76.4 \pm$ $16.2 \%(7.64 \pm 1.62 / 10)$.

\section{Discussion}

Eccentric training appears to be indispensable in the treatment of tendinopathies. Animal and clinical studies have demonstrated their interest ${ }^{5,}, 23$. Up to now, the gold standard to deliver such exercise remain on an isokinetic dynamometer ${ }^{24}$. Different isokinetic protocols have been developed ${ }^{25}$. This one allows to control the speed of the movement, the intensity of the contraction and the tendino-muscular stretching, and permits to have a better control of the reeduca- 
tion. However, the accessibility of such dynamometer remains difficult. This is why non isokinetic rehabilitation protocols are developed.
After an intratendinous infiltration of PRP, it seems admitted that a reeducation protocol is necessary to improve the efficacy of this treatment ${ }^{6}$. However, up

Table 1. Post-infiltration physical therapy program.

\begin{tabular}{|c|c|}
\hline Week 1 & $\begin{array}{l}\text { - relatively rest - activities of daily living } \\
\text { - cryotherapy } \\
\text { - pain killers if necessary } \\
\text { - no NSAI drugs }\end{array}$ \\
\hline Week 2 & $\begin{array}{l}\text { - isometric strengthening of the quadriceps ( } 3 \text { sessions of } 15 \text { repetitions) } \\
\text { - eccentric exercises, knee bend at } 45^{\circ}, 3 \text { sessions of } 15 \text { repetitions, } 3 \text { times a week } \\
\text { - electromyostimulation } \\
\text { - stretching of the quadriceps } \\
\text { - cryotherapy }\end{array}$ \\
\hline Week 3 & $\begin{array}{l}\text { - cycloergometer (low resistance, } 10 \text { minutes) } \\
\text { - isometric strengthening of the quadriceps ( } 5 \text { sessions of } 15 \text { repetitions) } \\
\text { - eccentric exercises, knee bend at } 45^{\circ}, 5 \text { sessions of } 15 \text { repetitions, } 3 \text { times a week } \\
\text { - electromyostimulation } \\
\text { - stretching of the quadriceps } \\
\text { - cryotherapy }\end{array}$ \\
\hline Week 4 & $\begin{array}{l}\text { - cycloergometer (low resistance, } 10 \text { minutes) } \\
\text { - isometric strengthening of the quadriceps ( } 5 \text { sessions of } 20 \text { repetitions) } \\
\text { - eccentric exercises, knee bend at } 60^{\circ}, 3 \text { sessions of } 20 \text { repetitions, } 3 \text { times a week } \\
\text { - electromyostimulation } \\
\text { - stretching of the quadriceps } \\
\text { - cryotherapy }\end{array}$ \\
\hline Week 5 & $\begin{array}{l}\text { - cycloergometer (moderate resistance, } 10 \text { minutes) } \\
\text { - isometric strengthening of the quadriceps ( } 5 \text { sessions of } 20 \text { repetitions) } \\
\text { - eccentric exercises, knee bend at } 60^{\circ}, 5 \text { sessions of } 20 \text { repetitions, } 3 \text { times a week } \\
\text { - proprioception } \\
\text { - electromyostimulation } \\
\text { - stretching of the quadriceps } \\
\text { - cryotherapy }\end{array}$ \\
\hline Week 6 & $\begin{array}{l}\text { - cycloergometer (moderate resistance, } 10 \text { minutes) } \\
\text { - isometric strengthening of the quadriceps ( } 5 \text { sessions of } 20 \text { repetitions) } \\
\text { - eccentric exercises, knee bend at } 90^{\circ}, 3 \text { sessions of } 20 \text { repetitions, } 3 \text { times a week } \\
\text { - proprioception } \\
\text { - electromyostimulation } \\
\text { - stretching of the quadriceps } \\
\text { - cryotherapy }\end{array}$ \\
\hline Week 7 & $\begin{array}{l}\text { - cycloergometer (high resistance, } 10 \text { minutes) } \\
\text { - isometric strengthening of the quadriceps ( } 5 \text { sessions of } 20 \text { repetitions) } \\
\text { - eccentric exercises, on an inclined plane of } 25^{\circ}, \text { knee bend at } 60^{\circ}, 3 \text { sessions of } 20 \text { repetitions, } \\
3 \text { times a week } \\
\text { - proprioception } \\
\text { - electromyostimulation } \\
\text { - stretching of the quadriceps } \\
\text { - cryotherapy }\end{array}$ \\
\hline Week 8 to 12 & $\begin{array}{l}\text { - eccentric exercises, on a decline board of } 25^{\circ}, \text { knee bend at } 60^{\circ}, 3 \text { to } 5 \text { sessions of } 20 \text { repetitions, } \\
3 \text { times a week (without physical therapist supervision) } \\
\text { - reathletisation (function of the sport) with patellar taping or bracing } \\
\text { - strengthening of the quadriceps } \\
\text { - stretching of the quadriceps } \\
\text { - cryotherapy }\end{array}$ \\
\hline Week 13 to 52 & $\begin{array}{l}\text { - eccentric exercises, on an inclined plane, knee bend at } 90^{\circ}, 5 \text { sessions of } 20 \text { repetitions, } 2 \text { times a week } \\
\text { (without physical therapist supervision) = warming-up } \\
\text { - sport with patellar taping or bracing } \\
\text { - stretching of the quadriceps } \\
\text { - cryotherapy }\end{array}$ \\
\hline
\end{tabular}




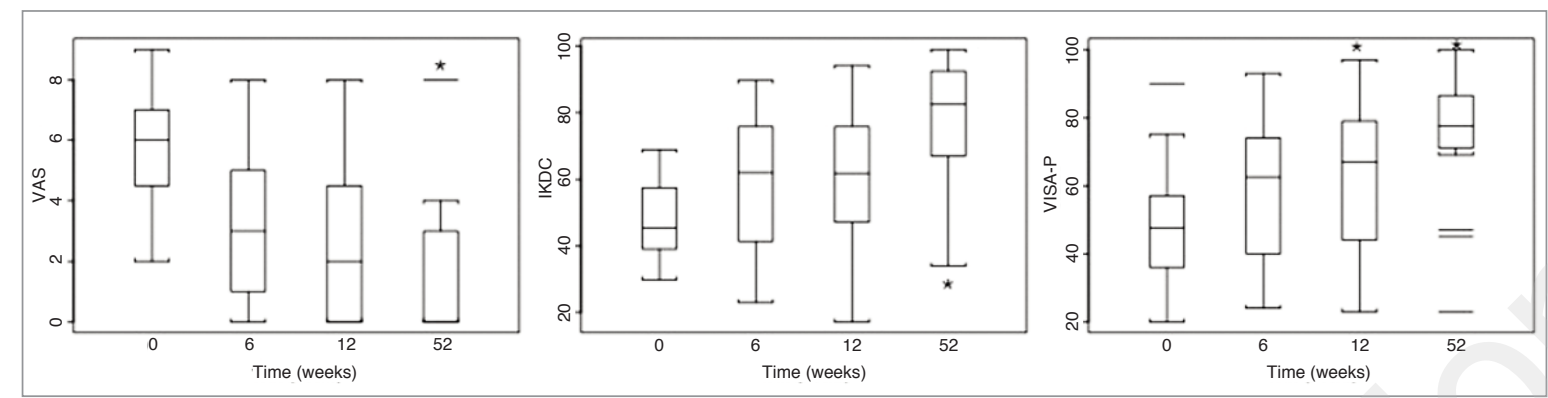

Figure 1. Results for the VAS, IKDC and VISA-P scores before infiltration, after 6 weeks, 3 months and 1 year. ${ }^{*} p<0.001$.

to now, these protocols were only succinctly or not described in the methods of the study. Moreover, these protocols vary a lot, even if eccentric exercises are generally prescribed. Only 3 papers described more extensively their reductive protocol ${ }^{7,15}$ 16 and from which one paper widely explain the post-infiltrative protocol of exercises ${ }^{16}$. This one is supervised during 3 months by a physical therapist and included eccentric exercises only after 1 month post-infiltration. However, due to limitation of the number of physiotherapy sessions by the Belgian National Institute for Health and Disability Insurance to 18 per year for a tendinopathy, our protocol had to be more accelerated followed by an auto-reeducation period.

Our protocol is based on sub-maximal eccentric reeducation under the pain threshold as recommended by Stanish $^{8}$. Indeed, it was demonstrated that eccentric exercises are more efficient to improve tendon structure than concentric ${ }^{5}$. It is very important that these exercises should be carry out under the pain threshold with a VAS below or equal to 2/10 (during warming-up, during and after exercises) to avoid new tendon lesions and compromise the healing process ${ }^{1,26}$. For this reason, first sessions were performed on the flat floor, the knee never exceeding the tip of the toes. Like that, constraint on the tendon, and also on the patella, are lesser than on a decline board ${ }^{27}$. However, after 6 weeks, in case of absence of pain, exercises could be done on a decline board of $25^{\circ}$, knee bend at $60^{\circ}$ maximum, the knee never exceeding the tip of the toes, to avoid too many pression on patella and tendon ${ }^{9}$. The exercises are progressively intensified in angulation and repetitions, but in case of pain, protocol return back the following step. This protocol is supervised by a physical therapist during 6 weeks (3 times a week), during which time patient learns exercises for its auto-reeducation ( 3 times a week for 6 other weeks) which is followed by maintenance exercises (2 times a week) up to 1 year. During reathletisation, eccentric exercises would not been done on the decline board but on flat floor as warm-up exercises (3 sessions of 15) before specific training. The compliance was good for the majority of the patients. Indeed, we explained to subjects that the healing process is initiated after the 6 first weeks but it could continue up to 6 or 12 months as ob- served clinically, and it is a necessity to follow supervised reeducation by an auto-reeducation.

It was demonstrated that a 24-week eccentric program on a decline board and, after 4 weeks, on an unstable surface with extra load was efficient for young volleyball players with patellar tendinopathy ${ }^{28}$. However, we thought that these instable exercises were too constraining after an infiltration of PRP, but proprioception was done separately after the fourth week after infiltration. Nevertheless, our eccentric program on flat floor showed a greater number of repetitions and bending knees up to $90^{\circ}$.

Each stage of the protocol must be performed under the pain threshold (VAS equal or below 2/10). The reathletisation could be initiated after the supervised physical therapy program (after 6 weeks), one more time under the pain threshold.

Even, if there is no general agreement, we observed in our previous study that 3 months could be a cut-off period to assess the efficacy of an infiltration of $\mathrm{PRP}^{7}$. In case of partial clinical improvement, a second infiltration could be realized or a surgical option could be discussed in case of the absence of improvement.

We demonstrated in our previous study that patients had often a weakness of the quadriceps (in concentric at $60 \%$ s as observed by isokinetics) ${ }^{7}$. Therefore isometric strengthening of this muscle associated to electromyostimulation was performed too. After each reeducation session, and later after sports activities, a local cryotherapy was recommended 29 . This one could be initiated with a taping or bracing to protect the tendon ${ }^{30}$.

The compliance of the auto-reeducation protocol was relatively good with more than $75 \%$, and was similar to the other study ${ }^{16}$. To improve the compliance, this auto-reeducation protocol was easy to perform at home or as the warm-up of the reathletisation protocol, required little time and was learned with the physiotherapist.

In this study, we did not made any functional evaluation or imagery because, these parameters never change significantly in our previous study while VAS and algo-functional scores (IKDC and VISA-P) were significantly improved ${ }^{7}$.

This study is based on the patellar tendon. However, even if we did not evaluate them in a clinical protocol, 
we adapted this standard sub-maximal protocol to epicondylitis, epitrochleitis and Achilles tendinopathies with good clinical results, over more than 250 tendon infiltrations of PRP.

\section{Conclusions}

Based on literature and our clinical experience, we developed reeducative protocol based on sub-maximal eccentric exercises added to PRP infiltrations in case of patellar tendinopathy. This 6 -weeks reeducative protocol supervised by a physical therapist must be followed by an auto-reeducation during reathletisation. After, maintenance exercises must be performed up to one year. This protocol is simple and allows a good compliance, but to confirm it's real efficiency, it should be useful to compare it to another one.

\section{Acknowledgements}

This study was supported by the Lejeune-Lechien Foundation and ADEPS Funds (associated foundation of the Léon Frédéricq Funds).

\section{References}

1. Kaux JF, Forthomme B, Le Goff C, Crielaard JL, Croisier JL. Current opinion on tendinopathy. J Sports Sci Med. 2011;10 238-253.

2. Smets F, Croisier JL, Forthomme B, Crielaard JM, Kaux JF. Applications cliniques du Plasma riche en plaquettes (PRP) dans les lésions tendineuses: revue de la littérature. Science \& Sport. 2012; 27:141-153.

3. Kaux JF, Drion P, Colige A, et al. Effects of platelet-rich plasma (PRP) on the healing of Achilles tendons of rats. Wound Rep Reg. 2012;20:748-756.

4. Virchenko O, Aspenberg P. How can one platelet injection after tendon injury lead to a stronger tendon after 4 weeks? Interplay between early regeneration and mechanical stimulation. Acta Orthop. 2006;77:806-812

5. Kaux JF, Drion P, Libertiaux V, et al. Eccentric training improves tendon biomechanical properties: a rat model. J Orthop Res. 2013;31:119-124.

6. Kaux JF, Crielaard JM. Platelet-rich plasma application to treat chronic tendinopathies: a review. Acta Orthop Belg. 2013;79: 10-15.

7. Kaux JF, Croisier JL, Bruyère $O$, et al. One injection of plateletrich plasma associated to a submaximal eccentric protocol to treat chronic jumper's knee. J Sports Med Phys Fitness, in press.

8. Stanish WD, Rubinovich RM, Curwin S. Eccentric exercise in chronic tendinitis. Clin Orthop Relat Res. 1986;208:65-68.

9. Zwerver J, Bredeweg SW, Hof AL. Biomechanical analysis of the single-leg decline squat. Br J Sports Med. 2007;41:264268.

10. Padulo J, Oliva F, Frizziero A, Maffulli N. Muscle, Ligaments and Tendons Journal - Basic principles and recommendations in clinical and field science. MLTJ. 2013;4:250-252.

11. Brown J, Sivan M. Ultrasound-guided platelet-rich plasma injection for chronic patellar tendinopathy: a case report. PM R. 2010;2:969-972.

12. Filardo G, Kon E, Della Villa S, Vincentelli F, Fornasari PM, Marcacci M. Use of platelet-rich plasma for the treatment of re- fractory jumper's knee. Int Orthop. 2010;34:909-915.

13. Gosens T, Peerbooms JV, Van Laar W, Den Oudsten BL. Ongoing positive effect of platelet-rich plasma versus corticosteroid injection in lateral epicondylitis: a double-blind randomized controlled trial with 2-year follow-up. Am J Sports Med. 2011.39:1200-1208.

14. Dragoo JL, Braun HJ, Durham JL, et al. Platelet-rich plasma as a treatment for patellar tendinopathy: a double-blind, randomized controlled trial. Am J Sports Med. 2014;42:610-618.

15. Vetrano M, Castorina A, Vulpiani MC, Baldini R, Pavan A, Ferretti A. Platelet-rich plasma versus focused shock waves in the treatment of jumper's knee in athletes. Am J Sports Med. 2013;41:795-803.

16. van Ark M, van den Akker-Scheek I, Meijer LTB, Zwerver J. An exercise-based physical therapy program for patients with patellar tendinopathy after platelet-rich plasma injection. Phys Ther Sport. 2013;14:124-130.

17. Charousset C, Zaoui A, Bellaiche L, Bouyer B. Are Multiple Platelet-Rich Plasma Injections Useful for Treatment of Chronic Patellar Tendinopathy in Athletes? A Prospective Study. Am J Sports Med. 2014; EPub February 11.

18. Bowman KFJr, Muller B, Middleton K, Fin C, Harner CD, Fu $\mathrm{FH}$. Progression of patellar tendinitis following treatment with platelet-rich plasma: case reports. Knee Surg Sports Traumatol Arthrosc. 2013;21:2035-2039.

19. Filardo G, Kon E, Di Matteo B, Pelotti P, Di Martino A, Mercacii M. Platelet-rich plasma for the treatment of patellar tendinopathy: clinical and imaging findings at medium-term follow-up. Int Orthop. 2013;37:1583-1589.

20. Kon E, Filardo G, Delcogliano M, et al. Platelet-rich plasma: new clinical application: a pilot study for treatment of jumper's knee. Injury. 2009;40:598-603.

21. Ferrero G, Fabbro E, Olandi D, et al. Ultrasound-guided injection of platelet-rich plasma in chronic Achilles and patellar tendinopathy. J Ultrasound. 2012;15:260-266.

22. Kaux JF, Le Goff C, Seidel L, et al. Comparative study of five techniques of preparation of platelet-rich plasma. Pathol Biol (Paris). 2011:59:157-160.

23. Frohm A, Saartok T, Halvorsen K, Renström P. Eccentric treatment for patellar tendinopathy: a prospective randomised short-term pilot study of two rehabilitation protocols. $\mathrm{Br} J$ Sports Med. 2007;41:e7.

24. Croisier JL, Foidart-Dessalle M, Tinant F, Crielaard JM, Forthomme B. An isokinetic eccentric programme for the management of chronic lateral epicondylar tendinopathy. $\mathrm{Br} \mathrm{J}$ Sports Med. 2007;41:269-275.

25. Forthomme B, Kaux JF, Crielaard JM, Croisier JL. Programme excentrique et tendinopathie: quels outils, quel programme? In Julia M, Hirt D, Croisier JL, Codine P, Hérisson C eds. Tendon et jonction tendino-musculaire - De la biomécanique aux applications thérapeutiques. Issy-les-Moulineaux; Elsevier Masson SAS. 2011; 91-97.

26. Cook JL, Purdam CR. Is tendon pathology a continuum? A pathology model to explain the clinical presentation of load-induced tendinopathy. Br J Sports Med. 2009;43:409-416.

27. Purdam CR, Jonsson $\mathrm{P}$, Alfredson $\mathrm{H}$, Lorentzon $\mathrm{R}$, Cook JL, Khan KM. A pilot study of the eccentric decline squat in the management of painful chronic patellar tendinopathy. $\mathrm{Br} \mathrm{J}$ Sports Med. 2004;38:395-397.

28. Biernat $\mathrm{R}$, et al. Rehabilitation protocol for patellar tendinopathy applied among 16- to 19-year-old volleyball players. J Strength Cond Res. 2014;28:43-52.

29. Reeves ND. Adaptation of the tendon to mechanical usage. $J$ Musculoskelet Neuronal Interact. 2006;6:174-180.

30. de Vries AJ, den Akker-Scheek IV, Diercks RI, et al. Effect of patellar strap and sports tape on jumper's knee symptoms: protocol of a randomised controlled trial. J Physiother. 2013;59:270. 